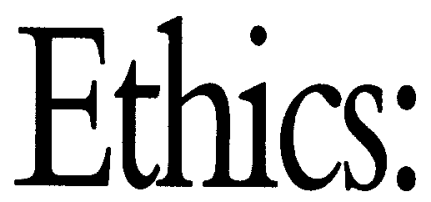

\title{
Communicating Standards and Influencing Behavior
}

by Betsy Stevens and Judi Brownell

Perhaps the strongest approach to communicating ethics is nonverbal-

that is, acting ethically.

$t$ has become a commonplace that demonstrating ethics is a good thing for an organization. Employees, managers, and top executives need to behave ethically so that the public can be confident that a company isn't engaging in illegal practices, that managers aren't harassing and threatening employees, and that line workers aren't stealing from the company or from guests. Perhaps a business can never have high enough ethical standards.

Simply saying that ethics is important risks begging the question, however. Instead, one needs to begin with the concept that ethical standards are guidelines for moral behavior. In a business context, ethical standards communicate a company's expectations about how employees will act when confronted with decisions that test their values. If a manager's goal is to cultivate ethical practices, that manager needs to learn everything possible about how to create, clarify, cultivate, and communicate standards of ethical behavior.

Normative ethics involves setting standards. It is often not enough simply to make a judgment call on whether or not an employee's actions are in an organization's best interests. It is also management's responsibility to influence organizational practices-to set standards

Betsy Stevens, Ph.D., is an assistant professor of managerial communication at the Cornell University School of Hotel Administration "eas7@ cornell.edu", where Judi Brownell, Ph.D., is professor of managerial communication and associate dean for academic affairs «jlb18@cornell.edu».

(C) 2000, Cornell University 


\section{Exhibit 1}

\section{Demographic information $(\mathrm{N}=101)$}

\begin{tabular}{|c|c|c|c|c|c|c|c|}
\hline \multirow[b]{3}{*}{ Hotel $1(n=58)$} & \multicolumn{2}{|c|}{ Gender } & \multirow[b]{2}{*}{ Supervisor } & \multicolumn{2}{|l|}{ Position } & \multicolumn{2}{|c|}{ Native language } \\
\hline & $\mathbf{M}$ & $F$ & & Employee & No answer & English & Other \\
\hline & 26 & 32 & 19 & 32 & 7 & 44 & 14 \\
\hline Hotel $2(n=43)$ & 17 & 26 & 12 & 31 & 0 & 32 & 11 \\
\hline Total sample & 43 & 58 & 31 & 63 & 7 & 76 & 25 \\
\hline
\end{tabular}

regarding which behaviors are desirable and should be continued, and which are negative and should be discouraged. The goal is to set standards that can be used as a basis for judgments regarding what is and is not ethical behavior. Not only is this a difficult job, but if managers fail to set the standards they will instead be set by the employees themselves according to whatever standards they have learned elsewhere.

To the extent that managers are effective in creating and maintaining ethical values, they are influencing the organization's culture and shaping employees' attitudes. In the end, achieving desired ethical outcomes comes down to effective communication. Managers who take responsibility for ensuring the ethical practices of their employees - and for defining the nature of ethical behavior-need to communicate those situational and multifaceted expectations frequently and effectively.

Just as it is often difficult to initiate discussions of sex and drugs with one's children, it is easier to think about ethical behavior than to talk about it with employees. Ethics, particularly in diverse organizational environments, remains a sensitive area. In fact, employees frequently believe that their own ethical standards are higher than those of the organization. ${ }^{1}$ Thus, not only must

${ }^{1} \mathrm{~T}$. Tyson, "Does Believing That Everyone Else Is Less Ethical Have an Impact on Work Behavior?,"Journal of Business Ethics, Vol. 11 (1992), pp. 707-717. managers' expectations be communicated clearly and consistently, but managers must model the desired behavior.

Trust, a sense of fairness, and individual respect are likely to increase as ethical frameworks are clearly defined ${ }^{2}$ and as employees share a common set of behavioral guidelines. The more clear and explicit this communication, the more likely a shared culture will develop. ${ }^{3}$ While the value of effective communication is stressed repeatedly in the management literature, ${ }^{4}$ experienced managers know how easily messages are distorted, misinterpreted, or lost entirely as they travel through organizational layers. ${ }^{5}$ The question is how to ensure that effective communication takes place.

Two central questions must be answered regarding effectively communicating ethics-related messages to employees. These are: How can ethical values best be communicated to employees?, and Who should talk to employees about ethical behavior? With the answers to those questions one can design effective com-

\footnotetext{
${ }^{2}$ J.L. Badaracco and R.R. Ellsworth, Leadership and the Quest for Integrity (Boston: Harvard Business School, 1989), p. 105.

${ }^{3}$ A. Singhapakedi, C. Roa, and S. Vitell, "Ethical Decision-making: An Investigation of Services-marketing Professions," Journal of Business Ethics, Vol. 15 (1996), pp. 635-644.

${ }^{4}$ For example, see: K.E. Weick and L.D. Browning, "Argument and Narration in Organizational Communication," Journal of Management, Vol. 12, No. 2 (1986), pp. 243-259.

${ }^{5} \mathrm{G}$. Goldhaber, Organizational Communication (Dubuque, IA: Wm. C. Brown, 1990), p. 154.
}

munication strategies for an organization.

To examine those questions, we conducted an exploratory study at two hotels. We used information gained from an employee survey on the communication of ethical standards to formulate four specific strategies for increasing awareness of organizational ethics. This paper first summarizes key findings from the survey and then suggests how that information might be helpful in providing direction to managers. Although the findings are limited and may not be entirely generalizable, this approach provides a model for managers who are interested in clearly and consistently communicating ethical standards.

\section{Sources and Channels}

The purpose of our exploratory study was to determine the channels through and sources from which hotel employees most frequently receive information about their organization's ethical standards. We expected that having specific information on organizational practices would provide direction to managers seeking a better understanding of how to communicate their companies' ethical standards.

We developed a questionnaire to obtain detailed information on organizational communication practices associated with information on ethical standards. We adapted our instrument from a survey developed earlier to assess the communication of organizational messages related to service quality. ${ }^{6}$ The ethics questionnaire provided a list of information channels and sources and asked respondents to indicate, on fivepoint Likert-type scales, the extent to which each contributed to their understanding of the property's

\footnotetext{
${ }^{6} \mathrm{~J}$. Brownell and D. Jameson, "Getting Quality Out on the Street: A Case of Show and Tell," Cornell Hotel and Restaurant Administration Quarterly, Vol.37, No. 1 (February 1996), pp. 28-33.
} 
ethical standards. (Choices ranged from "learned nothing" to "learned a great deal.") Channels included face-to-face communication, telephone, memos, e-mail, faxes, or ethical codes. Sources included an immediate supervisor, the general manager, guests, and family and friends. We also asked participants to indicate the level of their satisfaction with the organization's ethical standards and whether they believed those standards had been communicated clearly to them. Finally, the survey also collected demographic information.

The study was conducted at two upscale hotels from the same chain, each in the business district of a large midwestern city. Each property comprises about 300 rooms and offers three food-service outlets. The general managers in each location approved the study. The human-resources directors included the survey with employee paychecks and followed up with memos to encourage participation. Using this methodology, the survey was distributed to all 215 employees, 121 employees at property 1 and 94 at property 2 . We received back a total of 101 usable surveys, for an overall response rate of 47 percent (58 surveys from property 1 and 43 from property 2 ). Although not overwhelming, we deemed this response rate sufficient to provide reliable results, and we attempted no second mailing.

The questionnaires were returned by 43 men and 58 women. Thirtyone supervised at least one other person while 63 said they did not (and seven failed to respond to this question). All but 25 respondents were native English speakers (see Exhibit 1).

\section{Sources of Ethical Learning}

Of nine different channels, training programs earned the highest mean (3.21) as a means for transmitting

\section{Exhibit 2}

\section{Channels for ethics information}

Training programs
Coaching
Reading manuals or other documents
Reading ethical codes
Watching other employees
Watching managers
Meetings with managers
Memos from managers
Participating in meetings

\begin{tabular}{c} 
Mean \\
\hline 3.21 \\
3.17 \\
3.11 \\
3.09 \\
3.09 \\
3.09 \\
2.99 \\
2.91 \\
2.80
\end{tabular}

\begin{tabular}{c}
$S^{*}$ \\
\hline 1.17 \\
1.11 \\
1.16 \\
1.24 \\
1.18 \\
1.25 \\
1.16 \\
1.19 \\
1.25
\end{tabular}

*Standard deviation

Means are based on a five-point Likert-type scale ranging from $1=$ no influence whatsoever to $5=$ considerable influence.

\section{Exhibit 3 \\ Sources for ethical guidance}

\begin{tabular}{|c|c|c|c|c|c|c|}
\hline & \multicolumn{2}{|c|}{ Total Sample } & \multicolumn{2}{|c|}{ Supervisors } & \multicolumn{2}{|c|}{ Employees } \\
\hline & Mean & SD* & Mean & $\mathbf{S D}^{*}$ & Mean & $\mathbf{S D}^{*}$ \\
\hline Family and friends & 3.57 & 1.38 & 3.52 & 1.25 & 3.60 & 1.43 \\
\hline Fellow employees & 3.07 & 1.15 & 3.08 & 1.03 & 3.06 & 1.97 \\
\hline Talks with supervisor & 2.97 & 1.28 & 3.41 & 1.19 & 2.75 & 1.13 \\
\hline Talks with GM & 2.73 & 1.43 & 3.13 & 1.39 & 2.54 & 1.42 \\
\hline Talks with guests & 2.36 & 1.27 & 2.20 & 1.32 & 2.44 & 1.10 \\
\hline Talks with guests or clients & 2.47 & 1.21 & 2.20 & .86 & 2.60 & 1.44 \\
\hline \multicolumn{3}{|l|}{ Overall Satisfaction... } & Mean & \multicolumn{2}{|r|}{$\mathbf{S D}^{*}$} & \\
\hline \multicolumn{2}{|c|}{...with organization's ethical standards } & \multicolumn{2}{|c|}{2.51} & \multicolumn{2}{|r|}{1.07} & \\
\hline \multicolumn{2}{|l|}{...with clarity of communication } & \multicolumn{2}{|c|}{2.47} & \multicolumn{2}{|r|}{.98} & \\
\hline *Standard deviation & & & & & & \\
\hline
\end{tabular}

information about ethics (Exhibit 2). This finding reflected the continuous teaching and training that occurred at both properties. Coaching was a close second, at 3.17 , followed by reading manuals and other documents (3.11), reading ethical codes (3.09), watching managers (3.09), and watching employees (3.09). Meetings with and memos from managers were viewed as less important. Participating in general meetings, in last place with a mean of 2.80 , was seen as the least important channel for learning about ethical standards.

Notwithstanding the channels for disseminating ethical information, the chief source of ethical information is family and friends (mean 3.57, see Exhibit 3). That is, employees spent considerably 
more time discussing ethics with family and friends than with supervisors and co-workers. Indeed, means declined dramatically for workplace sources. Talks with other employees achieve a mean of 3.07 ; direct supervisors, 2.97 ; and the general manager, 2.73 .

With regard to their overall satisfaction, respondents indicated that they were "somewhat" satisfied (mean of 2.51) with the organization's ethical standards and also with the clarity with which these standards were communicated (mean of 2.47).

T-tests revealed no significant gender differences regarding either the channels or sources of ethical standards. The only significant differences occurred in the results from supervisory and non-supervisory employees. Supervisors reported that they engaged in more discussions about ethics with both the general manager $(t=2.70)$ and with their own direct supervisor $(t=2.73)$ than did non-supervisory employees.

Given this finding, one might wonder why supervisors are not having a stronger ethical effect on their line employees. Perhaps it's because, as we have seen, the communication of ethical standards “doesn't just happen." Managers must take deliberate and thoughtful action to ensure that their organizations establish and maintain guidelines for ethical practices. The results of this study suggest several useful ideas for managers with regard to how ethical standards can be communicated most effectively, as we discuss next.

\section{Guidelines for Communicating Organizational Ethics}

The first step in communicating ethics is to pay more attention to how ethical standards are communicated. Given the indifferent response employees gave to the question about how satisfied they were with the way the organization communicated its ethical standards, it appears that those employees would accept increased communication regarding ethical standards. The study suggests that at least four methods are effective in communicating ethics (see Exhibit 2). Those are (1) create ethical codes and make sure they appear in employee manuals and other documents; (2) conduct training programs on ethical standards;

(3) coach employees and ask them to coach others; and (4) model desired behavior.

Establish clear standards. One common response from companies seeking to publicly demonstrate their attention to organizational ethics has been the creation of ethical codes. ${ }^{7}$ The advantage of a code, often expressed as part of the company's mission statement, is that it is a written document that can be clearly and accurately communicated to all employees.

General Motors Corporation, for instance, has amended its policy on gifts and gratuities and has taken a much tougher stance on lavish corporate entertainment. Kmart also has a code explicitly prohibiting bribes, commissions, and kickbacks and further requires outside vendors to pledge they will not engage in such behavior with employees. ${ }^{8}$

Hospitality companies, too, have developed ethical codes. Issues related to conflict of interest, personal character, customer relations, and gifts are among the most common topics found in the ethical codes

\footnotetext{
${ }^{7}$ For example, see: L.J. Brooks, “Corporate Codes of Ethics," Journal of Business Ethics, Vol. 8 (1989), pp. 117-119; and B. Stevens, "An Analysis of Corporate-ethical-code Studies: Where Do We Go from Here?," Journal of Business Ethics, Vol. 13, pp. 63-69.

${ }^{8}$ G. Stern and J.S. Lublin, "New GM Rules Curb Wining and Dining," Wall Street Joumal, June 5, 1996, p. B1.
}

developed by hotels. ${ }^{9}$ Codes are important managerial documents because they institutionalize ethics. While many properties have employee-friendly codes framed in language that supports employee efforts, at the other extreme is a code that provides what its authors refer to as "rules and penalties."

Creating an ethical code, however, is not enough. All of an organization's print materialsemployee handbooks, manuals, personnel policies and procedures, and other documents - must clearly and consistently reinforce the standards set out in the code itself. Equally important is paying attention to implementing the code so that it is understood and practiced by employees. That occurs first during training and orientation.

\section{Address ethics during train-} ing. Effective employee orientation requires that ethical standards be part of the message new employees receive about the organization. While neither property in our study conducted training sessions focused exclusively on ethical behavior, ethics was addressed in a number of training programs. Indeed, employees reported that those training programs were the major channel for learning managerial expectations about ethics.

Formal training ensures that all employees hear the same organizational message. Without a strong orientation program and formal training to make expectations explicit, those employees are likely to rely on their previous experiences rather than on the company's standards. Employees need and depend on managers' help in clarifying their understanding of the organizational

\footnotetext{
${ }^{9} \mathrm{~B}$. Stevens, "Business Communication and the Ethical Context," in Effective Business Communication, 7th edition, ed. H. Murphy, H. Hildebrandt, and J. Thomas (New York: McGraw-Hill, 1997), pp. $95-116$.
} 
culture and standards of ethical behavior. By providing a clear framework, employees will learn important policies and support common organizational goals.

While training and orientation programs are essential, ethical standards must become part of the organizational culture, interwoven into the organizational fabric so that both managers and employees are clear and consistent in their view of what constitutes ethical behavior. Codes of conduct cannot be imposed on employees who do not accept or share the corporate values. Those shared values are critical to determining how members perceive problems and make decisions. In addition to creating ethical codes and communicating them through formal training programs, managers must establish and maintain the basic values that support ethical practices. The communication of those values throughout the organization is best accomplished through coaching and modeling ethical behavior.

\section{Reinforce standards through} coaching. A powerful means of communicating ethics, coaching is the ongoing process of assessing employee performance and providing constructive feedback for the purpose of clarifying performance standards and motivating employees to improve job performance. ${ }^{10}$ One of these performance standards must address the employee's ethical behavior.

While training is a formal and structured activity used to impart new skills or knowledge, coaching is less formal and is provided individually. It is a form of on-the-job training whereby the manager provides the specific information or feedback

\footnotetext{
${ }^{10}$ L.W. Hillman et al., "Enhancing Staff Members' Performance through Feedback and Coaching," Journal of Management Development, Vol. 11, No. 2 (1990), pp. 20-27.
}

each employee needs to understand and demonstrate the organization's ethical standards. ${ }^{11}$ As each employee is likely to hold somewhat different personal values and perspectives, coaching allows one to accommodate those differences in providing feedback.

Coaching facilitates a collaborative manager-employee relationship. The goal is for each employee to recognize the importance of meeting the ethical standards that have been set and to participate in an ongoing process of ensuring that the standards are achieved each day. Effective coaching encourages each person to take responsibility for his or her actions and to understand how they fit into the organization's framework.

Model desired behavior. Employees pay attention to what their managers do, and they learn about the standards and values of the organization by watching senior executives. Whether intentionally or not, the manager is the employees' role model-particularly in the case of ethical behavior. Modeling behavior effectively requires one to be clear about what constitutes acceptable practices and which practices are not acceptable. Finally, it hardly needs to be said that employees will pay attention to what a manager does over what the manager says.

Our survey did not expressly ask the hotel employees whether their ethical behavior has been shaped by the workplace. The respondents did, however, indicate that they were well aware of the hotel managers' efforts to provide guidance on ethics. Although the values we hold are developed in early childhood, it seems reasonable to believe that the standards we set for ourselves and others can be modified through

\footnotetext{
"B. Gerber, "From Manager to Coach," Training, February 1992, pp. 25-31.
}

training, coaching, and modeling. This assumption is the base on which organizational cultures are created. That is, regardless of what values and attitudes individuals have when they enter the workplace, all employees are expected to adapt their behavior to the standards of the organization. This is possible only if the organization provides guidelines that create a common, shared experience for its members. One dimension of these guidelines addresses ethical standards.

Setting organizational standards requires that managers clearly articulate desired values and practices. In addition to routine policies and procedures, an ethical code has the potential to influence employee behavior substantially. Only when the code is communicated clearly and consistently, through both formal and informal channels, will it be effective in accomplishing its purpose.

The most direct way of communicating ethical standards is to incorporate the ethical code into all appropriate print materials developed by the organization. In the study reported here, employees indicated that they learned about organizational ethics from reading documents. Respondents also confirmed the value of training and orientation programs. Coaching and modeling, the employees at the two properties further suggest, are effective means of incorporating ethical learning into their daily practices.

The bottom line is this: As a manager, it is your responsibility to ensure that ethical standards are well formulated and documented as ethical codes. Only when those standards are communicated in ways that employees find meaningful will they be practiced. You cannot underestimate the important role you play in this process. Ca 